\title{
Using deuterated PAH amendments to validate chemical extraction methods to predict PAH bioavailability in soils
}

Article

Accepted Version

Gomez-Eyles, J. L., Collins, C. D. and Hodson, M. E. (2011) Using deuterated $\mathrm{PAH}$ amendments to validate chemical extraction methods to predict PAH bioavailability in soils. Environmental Pollution, 159 (4). pp. 918-923. ISSN 02697491 doi: https://doi.org/10.1016/j.envpol.2010.12.015 Available at https://centaur.reading.ac.uk/19043/

It is advisable to refer to the publisher's version if you intend to cite from the work. See Guidance on citing.

To link to this article DOI: http://dx.doi.org/10.1016/j.envpol.2010.12.015

Publisher: Elsevier

All outputs in CentAUR are protected by Intellectual Property Rights law, including copyright law. Copyright and IPR is retained by the creators or other copyright holders. Terms and conditions for use of this material are defined in the End User Agreement.

www.reading.ac.uk/centaur 
Central Archive at the University of Reading

Reading's research outputs online 


\section{methods to predict PAH bioavailability in soils}

3

4 Jose L. Gomez-Eyles ${ }^{\mathrm{a} *}$, Chris D. Collins ${ }^{\mathrm{a}}$ and Mark E. Hodson ${ }^{\mathrm{a}}$

5

6

${ }^{\text {a }}$ University of Reading, School of Human and Environmental Sciences, Soil

7 Research Centre, Reading, RG6 6DW, Berkshire, United Kingdom.

8

9

10

11

12

13

14

15

16

17

18

19

20

21

22

23

24 *Corresponding author. Tel: +44 1183787903 Fax: +44 1183786666

25 Email address: j.l.gomezeyles@ reading.ac.uk (J.L Gomez-Eyles) 


\section{Abstract}

Validating chemical methods to predict bioavailable fractions of polycyclic aromatic

29 hydrocarbons (PAHs) by comparison with accumulation bioassays is problematic.

30 Concentrations accumulated in soil organisms not only depend on the bioavailable

31 fraction but also on contaminant properties. A historically contaminated soil was 32 freshly spiked with deuterated PAHs (dPAHs). dPAHs have a similar fate to their 33 respective undeuterated analogues, so chemical methods that give good indications of 34 bioavailability should extract the fresh more readily available dPAHs and historic more recalcitrant PAHs in similar proportions to those in which they are accumulated

36 in the tissues of test organisms. Cyclodextrin and butanol extractions predicted the bioavailable fraction for earthworms (Eisenia fetida) and plants (Lolium multiflorum) better than the exhaustive extraction. The PAHs accumulated by earthworms had a larger $\mathrm{dPAH}: \mathrm{PAH}$ ratio than that predicted by chemical methods. The isotope ratio method described here provides an effective way of evaluating other chemical methods to predict bioavailability.

\section{Keywords}

44 Bioavailability; polycyclic aromatic hydrocarbons; earthworms; plants; deuterated

\section{Capsule}

A novel method using isotope ratios to assess the ability of chemical methods to predict PAH bioavailability to soil biota. 


\section{Introduction}

53 Prolonged contact times between organic contaminants and soil decrease the 54 bioavailability of these compounds for uptake by organisms or for degradation by 55 microorganisms in a process often referred to as 'ageing' (Belfroid et al., 1995; 56 Alexander, 2000; Northcott and Jones, 2001). Thus measuring the total concentration 57 of organic contaminants present at contaminated sites may lead to over conservative 58 risk assessments as only the bioavailable fractions can cause toxic effects. Recently, 59 approaches for ecological risk assessment have been developed where bioavailability 60 data, obtained from the results of bioassays are used (Harmsen, 2007). These 61 bioassays only respond to the bioavailable fraction of contaminants (Jensen and 62 Mesman, 2007), but their application can be time consuming and laborious. As a 63 result a number of more time- and cost-efficient chemical methods for predicting 64 bioavailability have been published in the scientific literature (Kelsey et al., 1997; 65 Reid et al., 2000; Ten Hulscher et al., 2003).

These chemical methods are normally validated in the literature by comparing how they approximate or correlate with the amount of organic compound accumulated by

69 soil biota such as earthworms and to a lesser extent plants, or the amount degraded by 70 microbes (Kelsey, et al., 1997; Tang and Alexander, 1999; Reid, et al., 2000; Liste 71 and Alexander, 2002; Tang et al., 2002; Ten Hulscher, et al., 2003). However, recent 72 studies have shown distinct differences between the PAHs extracted using some of 73 these techniques and those accumulated in earthworms and plants (Hickman and Reid, 74 2005; Bergknut et al., 2007; Gomez-Eyles et al., 2010). It is important to realise 75 however, that these methods are meant to provide a measure of bioavailability not 
76 bioaccumulation. Apart from being influenced by the bioavailability of the contaminant, the final concentration of an organic contaminant accumulated within a soil organism will also depend on the metabolic fate of the contaminant within the organism and the partitioning properties of the contaminant. Assessing chemical methods by comparing the concentration of a PAH they extract, with that accumulated in a soil organism is therefore not a fair test of their ability to predict PAH bioavailability (Gomez-Eyles et al., 2010).

An alternative way of assessing the ability of chemical methods involves predicting accumulation concentrations from concentrations measured by chemical methods and accounting for contaminant partitioning properties (Jonker et al., 2007; van der Heijden and Jonker, 2009). However these calculations do not account for differences in the metabolic fate of different contaminants and carry significant assumptions. When using passive sampling methods, like solid phase micro-extraction (SPME) fibres, these assumptions include using contaminant $K_{\mathrm{ow}}$ values as approximations for bioconcentration factors. When using mild solvent extractions (e.g. butanol) or depletive sampling extractions (e.g. cyclodestrin or tenax extractions) even further assumptions have to be made by using generically derived $K_{\mathrm{oc}}$ values (van der Heijden and Jonker, 2009). The latter is a very substantial assumption considering field contaminated soils have been shown to have $K_{\mathrm{oc}}$ values several orders of magnitude above generically derived ones (Hawthorne et al., 2002; Jonker, et al., 2007).

We propose a novel method to evaluate the ability of chemical extractions to predict PAH bioavailability to earthworms and plants that can account for differences in bioaccumulation concentrations caused by different contaminant properties. This 
101 method follows the same principle used in a previous study on the effect of ageing in sediments on PAH accumulation at the top levels of aquatic food chains (Moermond

103 et al., 2007). Here we spike a soil historically contaminated with PAHs, with

104 deuterated PAHs (dPAHs) enabling a comparison of the extraction and uptake of

105 freshly spiked PAHs and aged historic PAHs by chemical methods and accumulation

106 bioassays. dPAHs have been used as internal standards in many studies involving

107 PAHs as they have very similar properties to their respective undeuterated analogue

108 PAHs (Bucheli et al., 2004; Bergknut, et al., 2007). They should therefore also have

109 the same metabolic fate and partitioning properties as their respective undeuterated

110 analogue PAHs. Consequently, a method that correctly predicts the fraction of PAHs

111 available to earthworm and plants should extract the freshly spiked dPAHs and the

112 aged historic PAHs in a similar ratio to that in which they are accumulated within

113 earthworm and plant tissues. Comparing the ratio in which the chemical method

114 extract the PAHs with that in which it accumulates in the soil organism, enables a fair

115 assessment of these chemical methods to measure bioavailability. This cannot be

116 achieved by simply comparing the concentration of a compound accumulated in a soil

117 organism with that extracted by the chemical method.

118

119 This investigation aims to use this novel method to evaluate the ability of butanol and

120 cyclodextrin extractions, two of the most widely reported methods, to predict PAH

121 bioavailability to earthworm and plants in soils.

122

123 2. Experimental Section

\subsection{Soil spiking and ageing}


127 PAH-contaminated soil from a former gasworks site in the UK (Table 1) was passed 128 through a $2 \mathrm{~mm}$ sieve. The $<2 \mathrm{~mm}$ fraction was spiked using a single-step spiking/re129 hydration procedure (Reid et al., 1998) with a stock solution of deuterated PAHs

130 (Sigma Chemicals, Poole, UK) in acetone, to final concentrations of $30 \mathrm{mg} \mathrm{kg}^{-1}$ of $131\left[{ }^{2} \mathrm{H}_{8}\right]$ naphthalene, $\left[{ }^{2} \mathrm{H}_{10}\right]$ phenanthrene, $\left[{ }^{2} \mathrm{H}_{10}\right]$ pyrene and $10 \mathrm{mg} \mathrm{kg}^{-1}$ of $\left[{ }^{2} \mathrm{H}_{12}\right]$ 132 benzo(a)pyrene. After addition of the stock solution, the soil was left uncovered in a 133 fume cupboard for $24 \mathrm{~h}$ to ensure all the solvent had evaporated. After confirming 134 removal of the solvent by olfactory detection and checking for residual wetting in the 135 soil, the spiked soil was re-wetted to $60 \%$ of its water holding capacity. Samples of 136 the soil were taken immediately after re-wetting to determine initial PAH 137 concentrations. The remainder of the soil was used either in bioassays of 20 days 138 duration (see below) or transferred to loosely sealed amber glass jars and aged for 20 139 days at $20^{\circ} \mathrm{C}$.

141 The same procedure was followed using a control soil (Broughton Loam, Kettering, 142 UK) (Table 1), but this soil was spiked with fresh undeuterated PAHs as well as 143 dPAHs to the same final concentrations as above. Exposing plants and earthworms to 144 a soil freshly spiked with equal amounts of PAHs and dPAHs served as a control for 145 any potential preferential accumulation of one kind of PAH over the other. When 146 comparing ratios of dPAHs:PAHs between organisms and the chemical extractions 147 we assume there is no difference between the uptake processes or the metabolic fate 148 of dPAHs and PAHs within the organisms. Determining whether this assumption is 149 true is therefore important when using these ratios to evaluate the potential of the 150 chemical methods to predict the bioavailable fraction. 


\subsection{Soil extractions}

154 To determine the total amount of PAHs in the soils five replicate $4 \mathrm{~g}$ portions of soil

155 were agitated in $10 \mathrm{ml}$ of 1:1 by volume acetone/hexane mixture for 2 hours on an 156 orbital shaker (Orbital Shaker SO1, Bibby Sterilin Ltd, Stone, Staffordshire, UK) at $157250 \mathrm{rpm}$. After extraction the samples were left to settle for $30 \mathrm{~min}$, and then $2 \mathrm{ml}$ of 158 solution were placed in a test tube containing $0.1 \mathrm{~g}$ of dry sodium sulphate before 159 transferring to gas chromatography vials for analysis (LOD=0.05 mg kg-1). This 160 method was adapted from a mechanical shaking method previously reported to give 161 better recoveries than a Soxhlet extraction (Song et al., 2002).

162 Two different kinds of butanol extraction were carried out; a vortex extraction where $16310 \mathrm{~g}$ of soil were mixed in $15 \mathrm{ml}$ of butanol solvent and agitated for $120 \mathrm{~s}$ (Liste and 164 Alexander, 2002), and a shake (Reid et al., 2004) where $10 \mathrm{~g}$ of soil were mixed with $16515 \mathrm{ml}$ of butanol and placed on a rock and roll shaker for 12 hours. All butanol 166 extractions were passed through $0.45 \mu \mathrm{m}$ polytetraflouroethylene (PTFE) filters 167 obtained from Chromacoal Ltd (Welwyn Garden City, UK) and were replicated 5 168 times before analysis by GC/MS. The method detection limits were $0.01 \mathrm{mg} \mathrm{kg}^{-1}$ and $1690.015 \mathrm{mg} \mathrm{kg}^{-1}$ for the butanol mix and shake respectively.

171 Cyclodextrin extractions (Stokes et al., 2005) were carried out in replicates of 5 by 172 mixing $1.5 \mathrm{~g}$ of soil with a $25 \mathrm{ml}$ solution of 60-mM HPCD (Sigma Aldrich, Poole, 173 UK) in deionised water and agitating the mixture for 20 hours using an orbital shaker 174 at $250 \mathrm{rpm}$. The mixture was then centrifuged at $2500 \mathrm{rpm}$ using a Mistral $3000 \mathrm{i}$ 175 centrifuge (MSE Sanyo-Gallenkamp, Leicester, UK) for 15 minutes and the 
supernatant discarded. The resulting soil pellet was shaken with $25 \mathrm{ml}$ of deionised water for $10 \mathrm{~s}$, centrifuged again and the supernatant was again discarded to remove any remaining HPCD solution. The soil pellet was then exhaustively extracted using

179 the acetone/hexane mechanical shaking extraction described above. GC/MS analysis

180 of this exhaustive extraction measured the PAHs remaining in the soil after HPCD 181 extraction $\left(\mathrm{LOD}=0.07 \mathrm{mg} \mathrm{kg}^{-1}\right)$.

182

183 All soil extractions were carried out after 20 days, once the earthworm and plant 184 exposures had concluded. The extractions were carried out on both the soil that had 185 been left in loosely sealed amber glass jars and also on the soil that had been used in 186 the bioassays. An exhaustive acetone hexane extraction was also carried out on day 0 to determine the initial concentration of PAHs in the soils.

\subsection{Earthworm bioassays}

191 Earthworms (Eisenia fetida) were obtained from Blades Biological (Cowden, UK).

192 Only adult earthworms with a clitellum were used in the bioassays. Five earthworms were exposed to $250 \mathrm{~g}$ of the spiked soils at $20^{\circ} \mathrm{C}$ for 20 days in loosely sealed amber

194 glass jars; 20 days was selected for consistency with the plant bioassays. After 195 exposure, the earthworms were rinsed with water and kept on wet filter paper for $24 \mathrm{~h}$ 196 to allow them to clear their guts. They were then cleaned, weighed and frozen at -20

$197{ }^{\circ} \mathrm{C}$ before being ground with 7 times their weight of dry sodium sulphate using a 198 pestle and mortar. Earthworms were then extracted following a saponiphication 199 method to remove fat from the earthworms (Contreras-Ramos et al., 2008). This 200 consisted of adding $10 \mathrm{ml}$ of $0.5 \mathrm{M} \mathrm{KOH}$ and $10 \mathrm{ml}$ of a 1:1 acetone/hexane solvent 
201 mixture to the ground earthworm and ultrasonicating the mixture at $45^{\circ} \mathrm{C}$ for 1 hour.

202 The solvent layer was then cleaned on a deactivated silica column, pre-eluted with

$2035 \mathrm{ml}$ of hexane. The sample was then eluted with a further $5 \mathrm{ml}$ of hexane before being 204 concentrated down to $1 \mathrm{ml}$ under a stream of nitrogen prior to analysis by GC/MS. 205 Extraction efficiencies for all PAHs ranged between 80.2-103.5\%.

\subsection{Plant bioassays}

Rye grass (Lolium multiflorum) was grown for 20 days in the soils in a temperature

210 controlled greenhouse. The plants were harvested and the roots separated from the 211 soil. Root samples were rinsed and ultrasonicated with deionised water to ensure 212 complete removal of soil particles from the roots. The cleaned roots were freeze-dried 213 (Super Modulyo 12K Freeze Dryer, Edwards, Crawley, West Sussex, UK) overnight.

214 Once dried, the roots were ground, homogenized and weighed prior to ultrasonication 215 for 2 hours in $10 \mathrm{ml}$ of dichloromethane. The extracts were then concentrated down to $2161 \mathrm{ml}$ under a stream of nitrogen and passed through $0.45 \mu \mathrm{m}$ filters before being 217 transferred to GC vials. Solutions were analysed by GC/MS. Extraction efficiencies 218 for all PAHs ranged between 84.7-100.3\%.

\subsection{GC-MS analysis}

222 All samples were analysed using a Thermo Trace GC Ultra system equipped with a 223 Thermo TR-5MS capillary column (dimensions: $30 \mathrm{~m}$ x $250 \mu \mathrm{m}$ x $0.25 \mu \mathrm{m}$; Thermo 224 Scientific, Runcorn, UK) operating with helium as a carrier gas, coupled to a Thermo 225 ITQ 1100 mass spectrometer (MS) through a heated transfer line $\left(300{ }^{\circ} \mathrm{C}\right)$. The GC 
injector $\left(220^{\circ} \mathrm{C}\right)$ was operated in a pulsed splitless mode, $1 \mu \mathrm{l}$ aliquots were injected using an autosampler, and the $\mathrm{GC}$ oven was programmed to hold $60{ }^{\circ} \mathrm{C}$ for 3 min then ramped at $15^{\circ} \mathrm{C} / \mathrm{min}$ to $290{ }^{\circ} \mathrm{C}$, and held for 10 minutes. The MS was operated with the ion source at $220{ }^{\circ} \mathrm{C}$ and a damping flow of $0.3 \mathrm{ml} \mathrm{min}^{-1}$.

\subsection{Statistical Analysis}

Statistical analysis was perfomed using R 2.9.2 (R Development Core Team). Differences between the ratios of dPAH: PAH accumulated in the organisms and those extracted by the different chemical methods were tested by performing an

236 ANOVA after general linear modelling of the data. The general linear model was given a gamma distribution to account for the data being expressed as ratios.

\section{Results and Discussion}

\subsection{PAH loss from the spiked soils}

The loss of the freshly spiked 2 and 3-ringed PAHs and dPAHs (naphthalene and

244 phenanthrene) during the 20 days of exposure was more rapid than that of the freshly

245 spiked 4 and 5-ringed PAHs and dPAHs (pyrene and benzo(a)pyrene), as measured by

246 the mechanical acetone hexane extraction, in both the gasworks and Kettering loam

247 soils. This is consistent with previous reports that have shown a broad inverse

248 relationship between the rate of biodegration and the number of rings in the PAH

249 (Bossert and Bartha, 1986; Wild and Jones, 1993). Low-molecular weight PAHs are

250 also more susceptible to abiotic processes like volatilisation (Park et al., 1990). The 
251 loss of the freshly spiked 2 and 3-ringed PAHs during the 20 day exposures were

252 significantly lower in the gasworks soil than in the Kettering loam $(\mathrm{p}<0.01)$. The two

253 soils were not characterised in sufficient detail to provide conclusive reasons for this,

254 but it was probably occurred due to differences in physicochemical properties and

255 microbial activities between the soils.

257 There was no significant difference in the loss of the dPAHs relative to their

258 undeuterated analogues in all Kettering loam treatments $(\mathrm{p}<0.01)$. This is to be

259 expected as deuterated organic compounds are known to have very similar chemical

260 and physical properties to their undeuterated analogues. However, there was a

261 significantly smaller loss of naphthalene and phenanthrene from the soil used in the

262 plant bioassays compared to loss from the soil kept in amber glass jars and the soil

263 used for the earthworm bioassays $(\mathrm{p}<0.01)$. This was despite the plant bioassay soil

264 being left uncovered and in the light. These conditions are theoretically more

265 conducive to abiotic loss processes such as volatilization or photodegration. This

266 could indicate that most losses in this soil were due to biodegradation, and that the

267 relatively higher soil moisture in the loosely sealed amber glass jars may have

268 provided better conditions for microbial activity. There was a significantly larger

269 decrease in the pyrene and benzo(a)pyrene concentrations in the Kettering loam used

270 in the earthworm and plant bioassays relative to the soil that had not been exposed to

271 any organisms $(\mathrm{p}<0.01)$. Earthworms have been previously found to promote the

272 degradation of PAHs (Ma et al., 1995) and a number of plant species have been

273 shown to increase hydrocarbon degradation, although rye grass in particular had a

274 smaller effect than others and has been shown to even decrease rhizosphere PAH

275 degradation (Phillips et al., 2006; Phillips et al., 2008). 
277 The loss of historic PAHs from the gasworks soils was higher than previously

278 anticipated for a soil with contamination that had been ageing for decades. We

279 hypothesise that introducing some freshly available dPAHs may have stimulated the

280 microbial activity in the soil and induced the catabolism of some historic PAHs

281 (Bauer and Capone, 1988; Reid et al., 2002). There was a greater loss of the freshly

282 spiked deuterated naphthalene than that of its historic counterpart in both the soil that

283 was not exposed to any organisms and the soil that was exposed to plants $(\mathrm{p}<0.01)$.

284 However, this was generally not the case for the other dPAHs and their non-

285 deuterated PAH counterparts. Faster degradation of the fresh and theoretically more

286 available PAHs might have been expected, but the reduced losses relative to those in

287 the Kettering loam coupled with the hypothesised induced catabolism of the historic

288 PAHs may have prevented this from happening.

3.2 Comparing ratios of DPAH:PAH between chemical methods and earthworm

bioassays

The ratios of $\mathrm{dPAH}$ to PAHs in the spiked gasworks soil are highly variable compared to those in the spiked Kettering loam (Figure 1). Note naphthalene is not included in 298 these figures due to the low concentrations left in the soil after 20 days. However, it 299 should be noted that the gasworks soil was not spiked with exactly the same 300 concentration of dPAHs as the concentration of historic PAHs in the soil. The acetone 
301 hexane extraction therefore gives an indication of the actual ratio of dPAH:PAH in the soil.

Low concentrations of phenanthrene and deuterated phenanthrene accumulated in the earthworms exposed to the gasworks soil, resulting in highly variable accumulation ratios. Differences between the dPAH:PAH ratios accumulated in the earthworms and those extracted by the chemical methods are therefore not statistically significant. However, there are highly significant differences in the ratios of $\mathrm{dPAH}: \mathrm{PAH}$ accumulated in the earthworms exposed to the gasworks soil compared to those

310 extracted by the chemical methods for the heavier 4-5 ring PAHs (pyrene and

311 benzo(a)pyrene) $(\mathrm{p}<0.001)$. The ratios can be up to 6 times bigger in earthworm 312 tissues relative to some chemical methods when considering benzo(a)pyrene. This

313 implies that the benzo(a)pyrene fraction bioavailable to earthworms differs

314 significantly to that predicted by the chemical methods. Earthworms accumulate an

315 increasingly higher proportion of the fresh dPAHs with increasing PAH size.

316 Although the mode of toxicity of benzo(a)pyrene to earthworms is non-polar narcosis

317 it is a proven human carcinogen and as such is the main risk driver for many

318 contaminated sites in the UK. Heavier PAHs have been shown to have relatively

319 higher potencies as aryl hydrocarbon receptor agonists (Barron et al., 2004), and

320 benzo(a)pyrene has a relative carcinogenic potency several order of magnitude higher 321 than other PAHs like phenanthrene (Pufulete et al., 2004). Therefore it is important 322 for chemical methods to correctly assess the bioavailablity of benzo(a)pyrene. A large 323 number of investigations that attempt to validate the use of chemical methods to 324 predict bioavailability often only use smaller 3-4 ringed PAHs like phenanthrene as 325 models (Kelsey, et al., 1997; Tang and Alexander, 1999; Reid, et al., 2000; Liste and 
326 Alexander, 2002), so care must be taken when extrapolating these results to the

327 heavier more recalcitrant and toxic PAHs in soil.

329 It was expected that the dPAH:PAH ratios for the Kettering loam bioassays and

330 chemical extractions would be at or close to unity as the 2 different kinds of PAHs

331 were added on the same day and in equal concentrations to the soil. The results

332 corroborate this, indicating that dPAHs have a similar behaviour to that of their

333 analogue undeutrated counterparts. It is therefore safe to assume that any differences

334 between the ratio of dPAH:PAH accumulated by the earthworms or plants and the

335 ratios in the chemical extractions from the gasworks soil are because they are

336 accessing different pools of PAHs and not because of any inherent difference in the

337 uptake rate or metabolism of dPAHs and PAHs. This confirms that dPAH

338 amendments can provide a good indication of the ability of a chemical method to

339 predict the bioavailable fraction.

341 The fact that earthworms did not show signs of preferential accumulation of the 342 dPAHs relative to the PAHs in the Kettering loam therefore confirms that the 343 increased relative accumulation of the dPAHs from the gasworks soil is due to the 344 higher availability of these freshly spiked dPAHs to earthworms relative to the 345 historic PAHs. The chemical methods to predict bioavailability should have reflected 346 this by extracting dPAHs and PAHs in a similar ratio to that accumulated in the 347 earthworms. The concentrations of the different PAHs and dPAHs extracted by the 348 different chemical methods were examined to determine whether the reason for their 349 smaller dPAH:PAH ratios in the extractions relative to those in the earthworm were 350 due to chemical methods extracting less dPAHs than those accumulated in the 
351 earthworms, more of the historic PAHs than those accumulated in the earthworms, or 352 a combination of the two. The concentrations in the acetone hexane extractions, the 353 butanol mix and the cyclodextrin extractions indicated that the lower ratios were 354 caused by a combination of both factors, whereas the butanol shake extractions had 355 extracted higher concentrations of the historic PAHs. The concentrations of the 356 dPAHs in both butanol extractions were similar but the 12 hour shake extracted even 357 more of the historic PAHs, suggesting the increased contact time enabled the 358 extraction of the more recalcitrant historic PAHs. Earthworms were therefore found to 359 accumulate smaller amounts of historic PAHs than was predicted by any of the 360 chemical methods. This is probably due to the lower chemical activity of historic 361 PAHs relative to the freshly spiked dPAHs. Extraction methods like the ones used in 362 this study involve shaking which maximises chemical potential gradients and 363 minimises the kinetic constraints. This is not the case in the earthworm bioassays, 364 where there will be a kinetic limitation of PAH uptake into the earthworms. Methods 365 that provide a measure of the chemical activity of a substance, which is related to its 366 energetic state (Reichenberg and Mayer, 2006), could therefore give a better 367 indication of accumulation in soil organisms. Cyclodextrin and butanol extractions 368 give a measure of the bioaccessible concentration, which is the portion of the total 369 concentration that is or can become bioavailable (Alexander, 2000). This could 370 explain why some studies have found poor correlations between the amounts of PAHs 371 accumulated in earthworms and those extracted by butanol or cyclodextrin extractions 372 (Hickman and Reid, 2005; Bergknut, et al., 2007; Gomez-Eyles, et al., 2010). There 373 are a number of studies however in which butanol and cyclodextrin extractions 374 provide a better indication of the bioavailable fraction of an organic contaminant than 375 exhaustive extraction methods (Kelsey, et al., 1997; Liste and Alexander, 2002; 
376 Hartnik et al., 2008). This is also true in this investigation as despite being

377 significantly smaller than the ratio of dPAH:PAH accumulated in the earthworms, the

378 ratios of dPAH:PAH extracted by the cylcodextrin and 120s butanol extractions are

379 still closer to the bioassay values than the dPAH:PAH ratio of the exhaustive acetone

380 hexane extraction.

\subsection{Comparing ratios of dPAH:PAH between chemical methods and plant}

\section{bioassays}

The ratios of dPAH:PAH accumulated in the rye grass roots exposed to the gasworks soil are closer to those extracted by the chemical methods relative to the ratios accumulated in the earthworm tissues for pyrene and benzo(a)pyrene (Figure 2). Again most of the significant differences occur with the heavier 4-5 ringed PAHs. For pyrene all chemical extractions remove a significantly higher proportion of the historic PAHs except for the 120 s butanol extraction $(\mathrm{p}<0.05)$. The acetone hexane

391 and 12 hour butanol extraction also extracted a significantly higher proportion of the 392 historic benzo(a)pyrene than that which accumulates in the plant roots $(\mathrm{p}<0.01)$. This 393 is not the case for the cylodextrin and the 120s butanol extraction. The 120 s butanol 394 extraction and in some cases the cyclodextrin extraction therefore generally provide a 395 better indication of the fraction of PAHs available to plants than the more exhaustive 396 acetone hexane extraction. It is hard to validate these results in the literature as few 397 investigations have been carried out attempting to relate chemical methods to predict 398 bioavailability to plant accumulation, although in a previous investigation we found 399 that a number of chemical methods did not improve the description of the variation in 400 plant accumulation provided by an acetone hexane extraction (Gomez-Eyles, et al., 
401 2010). Tang and Alexander (1999) however found that a number of mild solvent

402 extractions including butanol correlated strongly with anthracene accumulation in

403 wheat and barley roots. No direct indication of how an exhaustive extraction

404 compared with this was given.

405

406 Plants accumulated a much lower proportion of the freshly spiked dPAHs than the 407 earthworms did. This could have occurred as plant roots are relatively static compared 408 to earthworms. When exposed to the spiked gasworks soil they are likely to deplete 409 the more readily available dPAHs surrounding them. The earthworms on the other 410 hand are more mobile and are therefore likely to come across areas of soil they have 411 not explored before. When exposed to these areas of soil, they will preferentially 412 accumulate a higher proportion of the more bioavailable dPAHs before they move on 413 to another area of soil where they will do the same. Differences in dPAH:PAH ratios 414 between plants and earthworms could also be due to the earthworm tissues being more

415 lipophilic than the root tissues causing more of the readily available dPAHs to 416 partition into their tissues. Other reasons could include differences in the PAH uptake 417 mechanisms between the two organisms.

\subsection{Conclusions}

421 In this investigation there are large differences between the ratios of dPAH:PAH

422 accumulated in plants relative to those accumulated in earthworms suggesting there

423 cannot be one sole chemical method to predict bioavailability. Factors like the

424 behaviour of different soil biota within the soil or their different lipid contents have an

425 important role in determining what fraction of a contaminant may or may not be 
available to them. It is extremely challenging if not impossible to develop a chemical method that is able to mimic soil organisms at a level in which differences between species can be accounted for. Although in some cases the ratios extracted by the chemical methods differ substantially from those accumulated in the earthworm tissues, results from this investigation do suggest that cyclodextrin and short butanol extractions extract a fraction of the PAHs which is closer to that bioavailable to earthworms and plants than that extracted by an exhaustive extraction. Deuterated PAH amendments could be used to evaluate the ability of other methods, like Tenax extractions (Ten Hulscher, et al., 2003), solid-phase microextraction (SPME) fibres

435 (Van der Wal et al., 2004), poly-oxymethylene solid-phase extractions (POM-SPE)

436 (Jonker and Koelmans, 2001), persulphate oxidations (Cuypers et al., 2000) or super

437 critical carbon dioxide extractions (Kreitinger et al., 2007), to predict PAH

438 bioavailablity to different soil biota. We believe that using this isotope ratio method 439 can enable the comparison of methods that give an indication of the chemical activity 440 of a contaminant (e.g.SPME or POM) with those that give an indication of 441 contaminant accessibility (e.g. Tenax or cyclodextrin). This is of particular interest as 442 previously comparisons between methods have been made by comparing correlations 443 between chemical methods and bioaccumulation assays, or by using equilibrium 444 partitioning calculations to make predictions. In the former approach the correlations 445 are largely affected by the partitioning and metabolism of the contaminant within the 446 organism whilst the latter approach involves substantial assumptions, particularly 447 when using measurements from mild solvent and depletive sampling extractions. We 448 also suggest using a representative 5-ringed PAH like benzo(a)pyrene in tests of 449 chemical extractions due to the importance of this class of PAH in risk assessment. It 450 is therefore of particular importance that the fraction of the benzo(a)pyrene extracted 
451 by the chemical methods examined in this investigation was the one that differed most 452 substantially from that accumulated in the earthworms. 


\section{Acknowledgements}

454

455 This study was funded by the Biotechnology and Biological Sciences Research

456 Council (BBSRC).

457

458

459

460

461

462

463

464

465

466

467

468

469

470

471

472

473

474

475

476

477 
480 Alexander, M., 2000. Aging, bioavailability, and overestimation of risk from 481 environmental pollutants. Environmental Science \& Technology 34, 4259-4265.

482 Barron, M.G., Heintz, R., Rice, S.D., 2004. Relative potency of PAHs and heterocycles as aryl hydrocarbon receptor agonists in fish. Marine Environmental Research 58, 95-100.

Bauer, J.E., Capone, D.G., 1988. Effects of co-occurring aromatic hydrocarbons on degradation of individual polycyclic aromatic hydrocarbons in marine sediment slurries. Appl. Environ. Microbiol. 54, 1649-1655.

Belfroid, A., Vandenberg, M., Seinen, W., Hermens, J., Vangestel, K., 1995. Uptake, bioavailability and elimination of hydrophobic compounds in earthworms (Eiseniaandrei) in field-contaminated soil. Environmental Toxicology And Chemistry 14, 605-612.

Bergknut, M., Sehlin, E., Lundstedt, S., Andersson, P.L., Haglund, P., Tysklind, M., 2007. Comparison of techniques for estimating PAH bioavailability: Uptake in Eisenia fetida, passive samplers and leaching using various solvents and additives. Environmental Pollution 145, 154-160.

Bossert, I.D., Bartha, R., 1986. Structure-biodegradability relationships of polycyclic aromatic-hydrocarbons in soil. Bulletin of Environmental Contamination and Toxicology 37, 490-495.

Bucheli, T.D., Blum, F., Desaules, A., Gustafsson, Ö., 2004. Polycyclic aromatic hydrocarbons, black carbon, and molecular markers in soils of Switzerland. Chemosphere 56, 1061-1076.

Contreras-Ramos, S.M., Alvarez-Bernal, D., Dendooven, L., 2008. Removal of polycyclic aromatic hydrocarbons from soil amended with biosolid or vermicompost in the presence of earthworms (Eisenia fetida). Soil Biology \& Biochemistry 40, 1954-1959.

Cuypers, C., Grotenhuis, T., Joziasse, J., Rulkens, W., 2000. Rapid persulfate oxidation predicts PAH bioavailability in soils and sediments. Environmental Science \& Technology 34, 2057-2063.

Gomez-Eyles, J.L., Collins, C.D., Hodson, M.E., 2010. Relative proportions of polycyclic aromatic hydrocarbons differ between accumulation bioassays and chemical methods to predict bioavailability. Environmental Pollution 158, 278-284.

Harmsen, J., 2007. Measuring bioavailability: From a scientific approach to standard methods. Journal of Environmental Quality 36, 1420-1428.

Hartnik, T., Jensen, J., Hermens, J.L.M., 2008. Nonexhaustive $\beta$-Cyclodextrin Extraction as a Chemical Tool To Estimate Bioavailability of Hydrophobic Pesticides for Earthworms. Environmental Science \& Technology 42, 8419-8425.

Hawthorne, S.B., Poppendieck, D.G., Grabanski, C.B., Loehr, R.C., 2002. Comparing PAH availability from manufactured gas plant soils and sediments with chemical and biological tests. 1. PAH release during water desorption and supercritical carbon dioxide extraction. Environmental Science \& Technology 36, 4795-4803.

Hickman, Z.A., Reid, B.J., 2005. Towards a more appropriate water based extraction for the assessment of organic contaminant availability. Environmental Pollution 138, 299-306. 
Jensen, J., Mesman, M., 2007. Ecological risk assessment of contaminated land: Bilthoven, The Netherlands.

Jonker, M.T.O., Koelmans, A.A., 2001. Polyoxymethylene solid phase extraction as a partitioning method for hydrophobic organic chemicals in sediment and soot. Environmental Science \& Technology 35, 3742-3748.

Jonker, M.T.O., van der Heijden, S.A., Kreitinger, J.P., Hawthorne, S.B., 2007. Predicting PAH bioaccumulation and toxicity in earthworms exposed to manufactured gas plant soils with solid-phase microextraction. Environmental Science \& Technology 41, 7472-7478.

Kelsey, J.W., Kottler, B.D., Alexander, M., 1997. Selective chemical extractants to predict bioavailability of soil-aged organic chemicals. Environmental Science \& Technology 31, 214-217.

Kreitinger, J.P., Quinones-Rivera, A., Neuhauser, E.F., Alexander, M., Hawthorne, S.B., 2007. Supercritical carbon dioxide extraction as a predictor of polycyclic aromatic hydrocarbon bioaccumulation and toxicity by earthworms in manufacturedgas plant site soils. Environmental Toxicology And Chemistry 26, 1809-1817.

Liste, H.H., Alexander, M., 2002. Butanol extraction to predict bioavailability of PAHs in soil. Chemosphere 46, 1011-1017.

Ma, W.C., Immerzeel, J., Bodt, J., 1995. Earthworm and food interactions on bioaccumulation and disappearance in soil of polycyclic aromatic hydrocarbons: Studies on phenanthrene and fluoranthene. Ecotoxicology and Environmental Safety 32, 226-232.

Moermond, C.T.A., Roessink, I., Jonker, M.T.O., Meijer, T., Koelmans, A.A., 2007. Impact of polychlorinated biphenyl and polycyclic aromatic hydrocarbon sequestration in sediment on bioaccumulation in aquatic food webs. Environmental Toxicology And Chemistry 26, 607-615.

Northcott, G.L., Jones, K.C., 2001. Partitioning, extractability, and formation of nonextractable PAH residues in soil. 1. Compound differences in aging and sequestration. Environmental Science \& Technology 35, 1103-1110.

Park, K.S., Sims, R.C., Dupont, R.R., Doucette, W.J., Matthews, J.E., 1990. Fate of PAH compounds in 2 soil types - Influence of volatilization, abiotic loss and biological-activity. Environmental Toxicology And Chemistry 9, 187-195.

Phillips, L.A., Germida, J.J., Farrell, R.E., Greer, C.W., 2008. Hydrocarbon degradation potential and activity of endophytic bacteria associated with prairie plants. Soil Biology \& Biochemistry 40, 3054-3064.

Phillips, L.A., Greer, C.W., Germida, J.J., 2006. Culture-based and cultureindependent assessment of the impact of mixed and single plant treatments on rhizosphere microbial communities in hydrocarbon contaminated flare-pit soil. Soil Biology \& Biochemistry 38, 2823-2833.

Pufulete, M., Battershill, J., Boobis, A., Fielder, R., 2004. Approaches to carcinogenic risk assessment for polycyclic aromatic hydrocarbons: a UK perspective. Regulatory Toxicology and Pharmacology 40, 54-66.

Reichenberg, F., Mayer, P., 2006. Two complementary sides of bioavailability: Accessibility and chemical activity of organic contaminants in sediments and soils. Environmental Toxicology And Chemistry 25, 1239-1245.

Reid, B.J., Fermor, T.R., Semple, K.T., 2002. Induction of PAH-catabolism in mushroom compost and its use in the biodegradation of soil-associated phenanthrene. Environmental Pollution 118, 65-73. 
Reid, B.J., Northcott, G.L., Jones, K.C., Semple, K.T., 1998. Evaluation of spiking procedures for the introduction of poorly water soluble contaminants into soil. Environmental Science \& Technology 32, 3224-3227.

Reid, B.J., Stokes, J.D., Jones, K.C., Semple, K.T., 2000. Nonexhaustive cyclodextrin-based extraction technique for the evaluation of PAH bioavailability. Environmental Science \& Technology 34, 3174-3179.

Reid, B.J., Stokes, J.D., Jones, K.C., Semple, K.T., 2004. Influence of hydroxypropylbeta-cyclodextrin on the extraction and biodegradation of phenanthrene in soil. Environmental Toxicology And Chemistry 23, 550-556.

Song, Y.F., Jing, X., Fleischmann, S., Wilke, B.M., 2002. Comparative study of extraction methods for the determination of PAHs from contaminated soils and sediments. Chemosphere 48, 993-1001.

Stokes, J.D., Wilkinson, A., Reid, B.J., Jones, K.C., Semple, K.T., 2005. Prediction of polycyclic aromatic hydrocarbon biodegradation in contaminated soils using an aqueous hydroxypropyl-beta-cyclodextrin extraction technique. Environmental Toxicology And Chemistry 24, 1325-1330.

Tang, J.X., Alexander, M., 1999. Mild extractability and bioavailability of polycyclic aromatic hydrocarbons in soil. Environmental Toxicology And Chemistry 18, 27112714.

Tang, J.X., Liste, H.H., Alexander, M., 2002. Chemical assays of availability to earthworms of polycyclic aromatic hydrocarbons in soil. Chemosphere 48, 35-42.

Ten Hulscher, T.E.M., Postma, J., Den Besten, P.J., Stroomberg, G.J., Belfroid, A., Wegener, J.W., Faber, J.H., Van der Pol, J.J.C., Hendriks, A.J., Van Noort, P.C.M., 2003. Tenax extraction mimics benthic and terrestrial bioavailability of organic compounds. Environmental Toxicology And Chemistry 22, 2258-2265.

van der Heijden, S.A., Jonker, M.T.O., 2009. PAH Bioavailability in Field Sediments: Comparing Different Methods for Predicting in Situ Bioaccumulation. Environmental Science \& Technology 43, 3757-3763.

Van der Wal, L., Jager, T., Fleuren, R., Barendregt, A., Sinnige, T.L., Van Gestel, C.A.M., Hermens, J.L.M., 2004. Solid-phase microextraction to predict bioavailability and accumulation of organic micropollutants in terrestrial organisms after exposure to a field-contaminated soil. Environmental Science \& Technology 38, 4842-4848.

Wild, S.R., Jones, K.C., 1993. Biological and abiotic losses of polynuclear aromatichydrocarbons (PAHs) from soils freshly amended with sewage-sludge. Environmental Toxicology And Chemistry 12, 5-12. 
Table 1. Chemical and physical properties of the soils.

\begin{tabular}{|l|l|l|l|l|l|}
\hline & $\mathrm{pH}$ & Total Organic Carbon (\%) & Sand (\%) & Silt (\%) & Clay (\%) \\
\hline $\begin{array}{l}\text { Kettering } \\
\text { loam }\end{array}$ & 7.1 & 1.99 & 66.9 & 21.7 & 11.8 \\
\hline $\begin{array}{l}\text { Gasworks } \\
\text { soil }\end{array}$ & 7.4 & 10.6 & 81.1 & 16.7 & 2.24 \\
\hline
\end{tabular}

618

619

620

621 